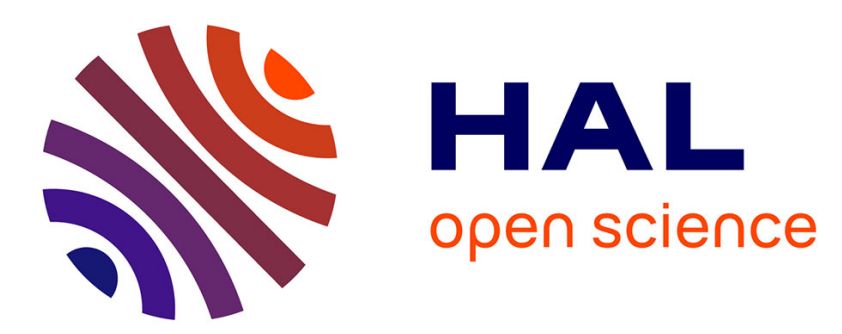

\title{
Redistribution of Metallic Impurities in Si during Annealing and Oxidation: $\mathrm{W}$ and $\mathrm{Fe}$
}

\author{
Alain Portavoce, Anthony de Luca, Nelly Burle, Michael Texier
}

\section{To cite this version:}

Alain Portavoce, Anthony de Luca, Nelly Burle, Michael Texier. Redistribution of Metallic Impurities in Si during Annealing and Oxidation: W and Fe. Defect and Diffusion Forum, 2018, 383, pp.17-22. 10.4028/www.scientific.net/DDF.383.17 . hal-02111609

\section{HAL Id: hal-02111609 \\ https://hal.science/hal-02111609}

Submitted on 26 Apr 2019

HAL is a multi-disciplinary open access archive for the deposit and dissemination of scientific research documents, whether they are published or not. The documents may come from teaching and research institutions in France or abroad, or from public or private research centers.
L'archive ouverte pluridisciplinaire HAL, est destinée au dépôt et à la diffusion de documents scientifiques de niveau recherche, publiés ou non, émanant des établissements d'enseignement et de recherche français ou étrangers, des laboratoires publics ou privés. 


\title{
Redistribution of Metallic Impurities in Si during Annealing and Oxidation: $\mathbf{W}$ and Fe
}

\author{
Alain Portavoce ${ }^{1, a^{*}}$, Anthony De Luca ${ }^{2,3, b}$, Nelly Burle ${ }^{2, c}$ and Michaël Texier ${ }^{2, d}$
}

${ }^{1}$ CNRS, IM2NP, Faculté des Sciences de Saint-Jérôme case 142, 13397 Marseille, France

${ }^{2}$ Aix-Marseille Université, IM2NP, Faculté des Sciences de Saint-Jérôme case 142, 13397 Marseille, France

${ }^{3}$ Present address: Materials Science \& Eng, Northwestern University, 2220 Campus Drive, Evanston, IL 60208

aalain.portavoce@im2np.fr, banthony.deluca@northwestern.edu, nelly.burle@im2np.fr, dmichael.texier@im2np.fr

${ }^{*}$ corresponding author

Keywords: Silicon, Diffusion, Oxidation, Tungsten, Iron.

\begin{abstract}
Atomic redistribution of $\mathrm{W}$ and $\mathrm{Fe}$ in $\mathrm{Si}$ were studied using secondary ion mass spectrometry and transmission electron microscopy. W diffusion experiments performed during isothermal annealing and during Si oxidation show that $\mathrm{W}$ atoms should use at least two different diffusion mechanisms. Experimental diffusion profiles can be well simulated by considering the simultaneous use of three different $\mathrm{W}$ diffusion mechanisms: the dissociative and the kick-out mechanisms, as well as an original mechanism based on the formation of a W-Si self-interstitial pair located on the interstitial Si sub-lattice. Fe redistribution was studied during the oxidation of a Fe-contaminated $\mathrm{Si}$ wafer. $\mathrm{Fe}$ is shown to be first pushed-out in $\mathrm{Si}$ by the mobile $\mathrm{SiO}_{2} / \mathrm{Si}$ interface, and thus to form Fe silicides at this interface. The silicide precipitates, which can exhibit a coreshell structure, appear to move with the $\mathrm{SiO}_{2} / \mathrm{Si}$ interface thanks to an oxidation/dissolution mechanism in the $\mathrm{SiO}_{2}$ and a nucleation/growth mechanism in the Si matrix. Furthermore, the rate difference between $\mathrm{Si}$ and Fe silicide precipitate oxidation leads to the formation of Si pyramidal defects at the $\mathrm{SiO}_{2} / \mathrm{Si}$ interface.
\end{abstract}

\section{Introduction}

It is well known that metallic contamination of silicon ( $\mathrm{Si}$ ) lead to strong device performance decay. They create deep levels in Si band gap behaving as acceptor or donor levels, decreasing minority carrier lifetime and minority carrier diffusion length. Furthermore, contaminated Si devices show significant leakage current. Due to microelectronic device size reductions, the current tolerable contamination concentration levels are particularly low $\left(\sim 10^{10} \mathrm{~cm}^{-2}\right)$. These very low levels cannot be detected with conventional surface analysis techniques such as Auger electron spectroscopy, X-ray photoelectron spectroscopy, and ultraviolet photoelectron spectroscopy, and are also too low to be detected with usual bulk analysis tools such as secondary ion mass spectrometry, complicating device failure analyses. It is thus necessary to identify contaminant possible effects on fabrication processes, and to be able to simulate contamination redistribution at levels lower than detection limits during device fabrication, in order to potentially identify their influence on device electrical properties [1-3].

Tungsten (W) contamination leads to significant device performance degradations [4-6], leading to the introduction of three different levels in Si gap at $\mathrm{E}_{\mathrm{c}}-0.59 \mathrm{eV}, \mathrm{E}_{\mathrm{v}}+0.33 \mathrm{eV}$ and $\mathrm{E}_{\mathrm{v}}+0.22 \mathrm{eV}$ [7]. W solubility in $\mathrm{Si}$ is expected to be high compared to other metals, with a maximum solubility limit higher than $10^{20} \mathrm{~cm}^{-3}$ at $1100{ }^{\circ} \mathrm{C}$ [6]. However, W diffusion kinetic is unknown, the few measurements performed to date suggesting diffusion kinetic similar to usual Si dopants [8]. Furthermore, these measurements suggest that $\mathrm{W}$ atoms use complex diffusion mechanisms 
different from the mechanisms of known metals [6-7,9]. Iron $(\mathrm{Fe})$ diffusion in Si is well known, since $\mathrm{Fe}$ is one of the most common contaminants in Si wafer due to multiple possible sources during microelectronic fabrication processes. Fe is a fast-diffusing specie in $\mathrm{Si}$ due to the use of the direct interstitial diffusion mechanism $[8,10]$. Fe solubility limit in $\mathrm{Si}$ is quite low, with a maximum close to $3 \times 10^{17} \mathrm{~cm}^{-3}$ at $1300{ }^{\circ} \mathrm{C}[10-11]$.

In the present work, the redistributions of $\mathrm{W}$ and $\mathrm{Fe}$ atoms in $\mathrm{Si}$ are investigated during thermal annealing and during $\mathrm{Si}$ thermal oxidation. In a first part, a detailed study of $\mathrm{W}$ diffusion is presented, showing that $\mathrm{W}$ probably uses an original diffusion mechanism, involving interstitial W-Si self-interstitial pair diffusion [12]. In the second part, the mechanisms involved with Fe redistribution at the mobile $\mathrm{SiO}_{2} / \mathrm{Si}$ interface during $\mathrm{Si}$ oxidation are presented, allowing $\mathrm{Si}$ pyramidal defect formation at this interface [13] to be understood [14].

\section{Experiments}

Commercial $n$-type phosphorus-doped $\mathrm{Si}(001)$ wafers were implanted with $\mathrm{W}$ or Fe atoms using the industrial implanter IMC200 developed by the company IBS. Ions were implanted at an angle of $7^{\circ}$ compared to the normal of the sample surface, with an ion beam energy of $165 \mathrm{keV}$ and $65 \mathrm{keV}$ for $\mathrm{W}$ and $\mathrm{Fe}$, respectively. Two types of samples were prepared with two different ion doses: $1 \times 10^{13}$ and $1 \times 10^{15}$ ions $\mathrm{cm}^{-2}$.

For diffusion experiments, the samples were pre-annealed at $776{ }^{\circ} \mathrm{C}$ for $1 \mathrm{~h}$ under vacuum (pressure $<10^{-7}$ Torr) in order to cure the samples from implantation-induced defects, creating an initial diffusion source that could be used as a reference state for following diffusion annealing. For oxidation experiments, the implanted samples were annealed at 900 or $1100{ }^{\circ} \mathrm{C}$ for various times under an $\mathrm{O}_{2}$ flux of 4-5 $\mathrm{L} \mathrm{min}^{-1}$.

Secondary ion mass spectrometry (SIMS) measurements were performed using a Cameca IMS 7F apparatus with a primary ion $\mathrm{O}^{+}$energy of $3 \mathrm{keV}$. High resolution (HR) transmission electron microscopy (TEM) and scanning transmission electron microscopy (STEM) high angle annular dark field (HAADF) analyses were performed using a FEI Titan 80-300 Cs-corrected microscope operating at $200 \mathrm{kV}$ and $300 \mathrm{kV}$.

\section{Results and Discussion}

W diffusion. Only samples implanted with the $1 \times 10^{13} \mathrm{~W} \mathrm{~cm}^{-2}$ dose were used for diffusion studies, as no defect could be detected by TEM in these samples after pre-annealing. In these samples, the $\mathrm{W}$ concentration is lower than the $\mathrm{W}$ solubility limit in $\mathrm{Si}$ in the temperature range investigated. The implantation of the $1 \times 10^{15} \mathrm{~W}$ dose in Si leads to $\sim 100$ nm-deep Si amorphization, and W-Si clusters form during subsequent annealing, degrading SIMS measurement accuracy [12]. Fig. 1 present SIMS profiles measured in the sample implanted with $10^{13} \mathrm{~W}$ at $\mathrm{cm}^{-2}$ after pre-annealing and different subsequent diffusion annealing. Annealing at $776{ }^{\circ} \mathrm{C}$ for 48 hours did not allow $\mathrm{W}$ diffusion, the profile after annealing (solid squares) being similar to the profile measured after pre-annealing (solid line). However, W diffusion occurred for annealing at higher temperatures for the same time. In this case, all the $\mathrm{W}$ atoms were mobile, but several singular behaviors can be noted on $\mathrm{W}$ diffusion profiles, which cannot be reproduced by classical Fickian diffusion models or usual models for dopant or metallic impurity diffusion in Si: i) the initial Gaussian distribution does not change into a flatter Gaussian distribution after diffusion as expected for classical Fickian diffusion, ii) the maximum concentration of the $\mathrm{W}$ distribution increases and shifts to the surface during annealing, iii) leading to a $\mathrm{W}$ diffusion profile exhibiting a quasi-linear shape. The observations related to the maximum concentration of the profiles could be explained by the well-known dissociative or kick-out diffusion mechanisms used by some metallic impurities in $\mathrm{Si}$ such as $\mathrm{Au}$ or Pt, promoting a 'U-shape' diffusion profile between the two surfaces of a Si wafer 
[15-16]. However, the linear shape of $\mathrm{W}$ diffusion profile could not be reproduced by these diffusion models.

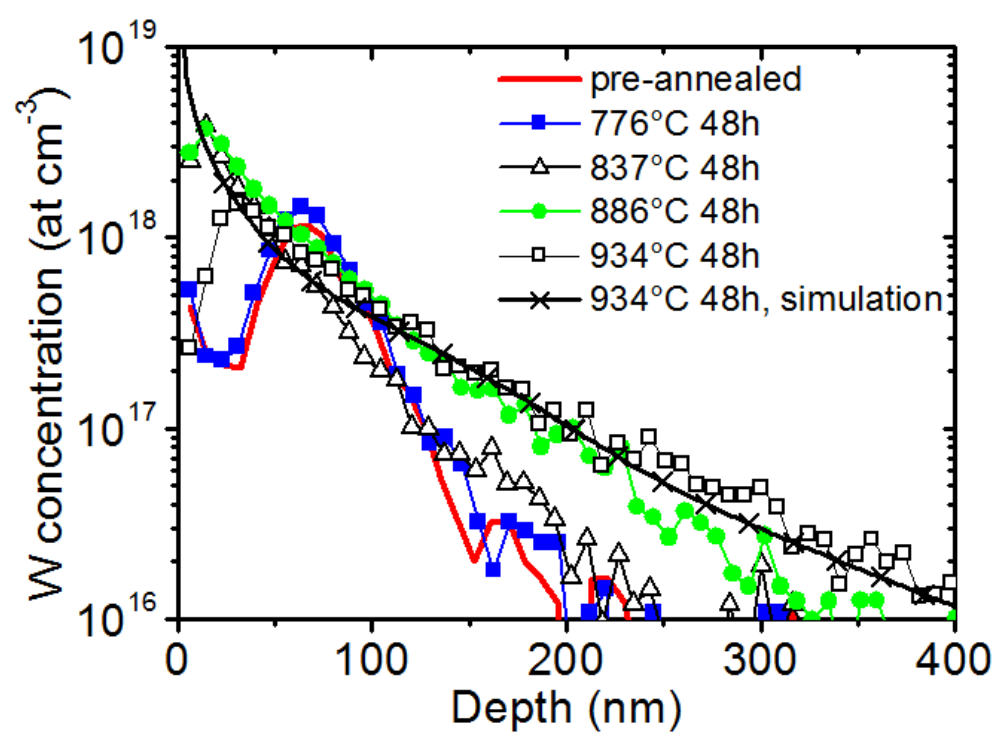

Fig. 1. W SIMS profiles measured after pre-annealing (solid line) and a subsequent diffusion annealing at 776 (solid squares), 837 (open triangles), 886 (solid circles), and $934{ }^{\circ} \mathrm{C}$ (open squares) for 48 hours. The cross line corresponds to the simulation of the annealing performed at $934{ }^{\circ} \mathrm{C}$ for $48 \mathrm{~h}$.

In order to better understand $\mathrm{W}$ atoms interactions with point defects, the samples implanted with a $\mathrm{W}$ dose of $1 \times 10^{15}$ ions $\mathrm{cm}^{-2}$ were oxidized at 900 and $1100{ }^{\circ} \mathrm{C}$. Fig. 2 presents TEM measurements performed on two pieces of a same sample after annealing at $900{ }^{\circ} \mathrm{C}$ for 3 hours with an $\mathrm{O}_{2}$ flux allowing for Si oxidation (Fig. 2a) or without oxygen (Fig. 2b). Si oxidation is known for injecting Si self-interstitials $(I)$ in Si [17-18]. In Fig. 2a we observe that in this condition W silicide clusters are formed in the Si substrate, while it is not observed after similar annealing without selfinterstitial injection (Fig. 2b), suggesting attractive chemical interactions between $\mathrm{W}$ atoms and $\mathrm{Si}$ self-interstitials. Furthermore, Fig. 3 shows that W diffusion is enhanced for a small fraction of W atoms (concentration lower than $\sim 2 \times 10^{17} \mathrm{~cm}^{-3}$ ) compared to without oxidation, suggesting that a fraction of $\mathrm{W}$ atoms uses a self-interstitial-mediated diffusion mechanism.

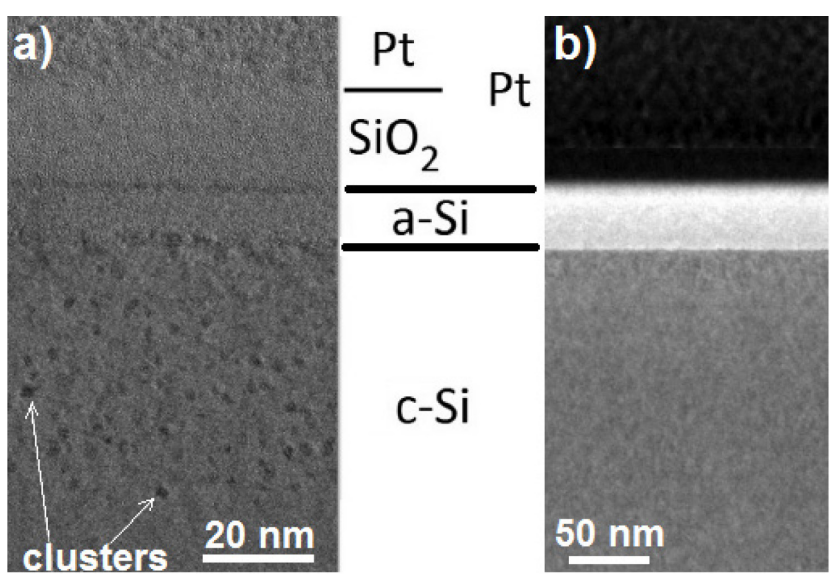

Fig. 2. Cross-sectional TEM images obtained on the sample implanted with a $\mathrm{W}$ dose of $1 \times 10^{15}$ ions $\mathrm{cm}^{-2}$, after annealing at $900{ }^{\circ} \mathrm{C}$ for 3 hours: a) with oxidation, and b) without oxidation.

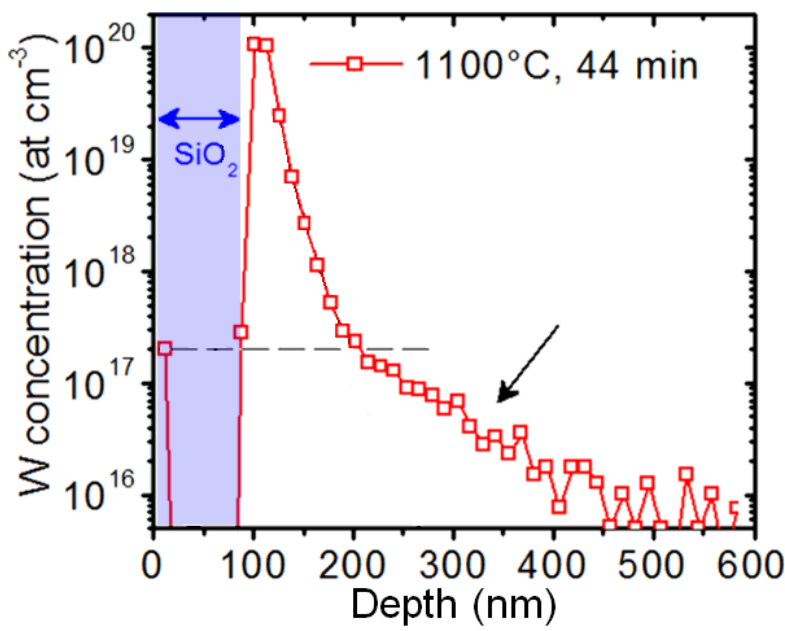

Fig. 3. SIMS profile showing the $\mathrm{W}$ distribution in the sample implanted with $1 \times 10^{15} \mathrm{~W}$ at $\mathrm{cm}^{-2}$, after oxidation at $1100{ }^{\circ} \mathrm{C}$ for 44 minutes. The arrow shows a diffusion tail observed for $C_{\mathrm{W}} \leq$ $2 \times 10^{17} \mathrm{~cm}^{-3}$.

Thus, we proposed that substitutional $\mathrm{W}$ atoms $\left(W_{s}\right)$ use simultaneously two different diffusion mechanisms based on three point-defect reactions in order to move in Si [6-7]: i) the dissociative mechanism $\left(W_{i}+V \Leftrightarrow W_{s}\right)$ using vacancies $(V)$, ii) the kick-out mechanism $\left(W_{i} \Leftrightarrow W_{s}+I\right)$, and iii) a mechanism based on the formation of an atomic pair $W I$, from an interstitial $\mathrm{W}$ atom $\left(W_{i}\right)$ and a $\mathrm{Si}$ 
self-interstitial $\left(W_{i}+I \Leftrightarrow W I\right)$. In this case, the experimental diffusion profiles can be reproduced as shown in Fig. 1 (cross line) [12]. W solubility limit was found to be close to $0.15 \%-0.2 \%$, and the diffusion coefficient of $\mathrm{W}$ atoms on interstitial sites was found to be $D_{W i}=5.59 \times 10^{-5} \exp$ $(-1.35 \mathrm{eV} / \mathrm{kT}) \mathrm{cm}^{2} \mathrm{~s}^{-1}$, while the diffusion coefficient of the $W I$ pair was found to be $D_{W I}=2.68$ $\times 10^{-5} \exp (-2.39 \mathrm{eV} / k T) \mathrm{cm}^{2} \mathrm{~s}^{-1}$.
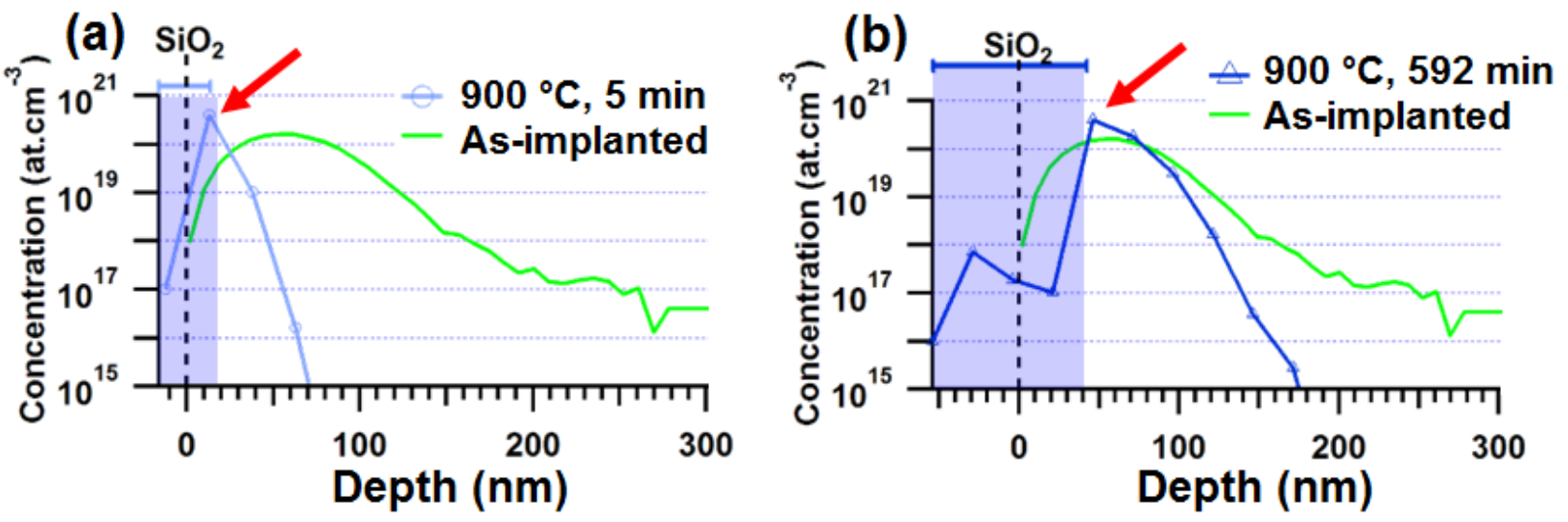

Fig. 4. Fe SIMS profiles measured in the Si substrate after implantation (solid line) and after oxidation at $900{ }^{\circ} \mathrm{C}$ (a) for $5 \mathrm{~min}$ (open circles), and b) for $592 \mathrm{~min}$ (open triangles). The colored area corresponds to the grown $\mathrm{SiO}_{2}$ layer. The arrow shows the location of the $\mathrm{Fe}$ concentration maximum after oxidation.

Fe redistribution. The study of oxidation of Fe-implanted Si substrates allowed six steps in the Fe redistribution process to be determined [14]. Fig. 4 presents Fe SIMS profiles measured after implantation (solid line) and after subsequent oxidation performed at $900{ }^{\circ} \mathrm{C}$ for 5 (Fig. 4a) and 592 minutes (Fig. 4b). As soon as Si oxidation starts (Fig. 4a, consumption of $6.6 \mathrm{~nm}$ of $\mathrm{Si}$ ) Fe atoms are pushed back into the $\mathrm{Si}$ substrate, leading to $\mathrm{Fe}$ accumulation at the $\mathrm{SiO}_{2} / \mathrm{Si}$ interface, corresponding to the first step of redistribution schematized in Fig. 5. The comparison between the profiles measured before and after oxidation in Fig. 4a shows that $\mathrm{Fe}$ atoms diffused into the substrate at concentrations significantly higher than the Fe solubility limit in Si. This effect could be related to $\mathrm{Si}$ self-interstitial injection resulting from the Si oxidation interfacial reaction. In the second step, due to the increase of the Fe concentration at the $\mathrm{SiO}_{2} / \mathrm{Si}$ interface during oxidation, $\mathrm{Fe}$ silicide precipitates form at this interface and grow in the Si substrate. Fig. 6-1 presents a TEM image of one of the Fe silicide precipitates formed at the $\mathrm{SiO}_{2} / \mathrm{Si}$ interface. The precipitates exhibit facets in the $\mathrm{Si}$ substrate, while their interface with the $\mathrm{SiO}_{2}$ layer is flat. Their orthorhombic structure corresponds to the phase $\beta-\mathrm{FeSi}_{2}$.

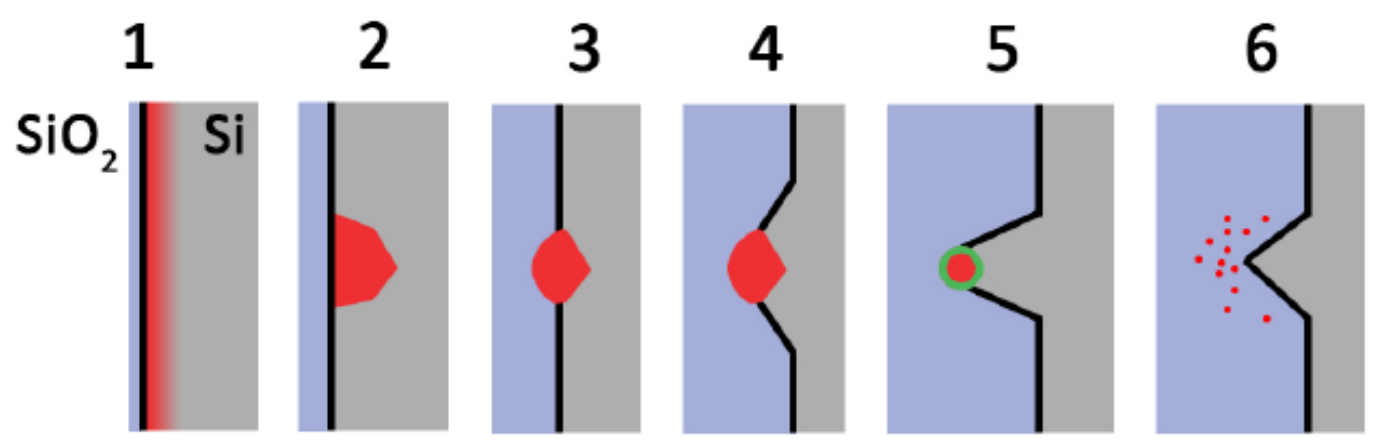

Fig. 5. Schematics showing the 6 steps observed during the oxidation of Fe-contaminated $\mathrm{Si}$ substrates (black line for the $\mathrm{SiO}_{2} / \mathrm{Si}$ interface, red color for Fe-rich regions and precipitates).

In a third step, while $\mathrm{Si}$ oxidation progresses, the $\mathrm{Fe}-\mathrm{Si}$ precipitates stay located on the mobile $\mathrm{SiO}_{2} / \mathrm{Si}$ interface, while part of their volume get incorporated in the $\mathrm{SiO}_{2}$ layer. Fig. 6-2 shows a TEM image of a $\beta$-FeSi $i_{2}$ precipitate at this stage (step 3 in fig. 5). Almost half of the precipitate is locate in $\mathrm{SiO}_{2}$ and half is located in $\mathrm{Si}$. It can be noted that the precipitate exhibits a spherical shape at the interface with amorphous $\mathrm{SiO}_{2}$, while its interface with monocrystalline $\mathrm{Si}$ is facetted. At that 
stage, the precipitates appear to move with the $\mathrm{SiO}_{2} / \mathrm{Si}$ interface (no precipitate could be detected in $\mathrm{SiO}_{2}$ and in Si by TEM), probably thanks to an oxidation/dissolution process of the precipitate in $\mathrm{SiO}_{2}$ and a growth process in $\mathrm{Si}$ supported by interfacial atomic diffusion. Later, due to the oxidation rate difference between $\mathrm{Si}$ and $\mathrm{Fe}$ silicide (Si oxidation faster than Fe silicide oxidation), the $\mathrm{SiO}_{2} / \mathrm{Si}$ interface get deeper than the clusters, forming a Si neck underneath the precipitates (step 4 in fig. 5). Furthermore, the push-out mechanism of $\mathrm{Fe}$ atoms from $\mathrm{SiO}_{2}$ to $\mathrm{Si}$ during the oxidation of $\mathrm{Fe}-\mathrm{Si}$ precipitates leads to a simultaneous increase of $\mathrm{Fe}$ atoms and decrease of $\mathrm{Si}$ atoms at the edge of the precipitates, promoting the formation of core-shell Fe silicide precipitates, with a Si-rich core corresponding to the initial $\beta$-FeSi ${ }_{2}$ phase (red color in step 5 in fig. 5) and a Fe-rich shell corresponding to the $\alpha^{\prime}-\mathrm{Fe}_{3} \mathrm{Si}$ phase (green color in step 5 in fig. 5). Fig. 6-3 presents a TEM image of a core-shell precipitate fully incorporated in the $\mathrm{SiO}_{2}$ layer, with the $\mathrm{Si}$ neck formed underneath, due to a masking-like effect of the cluster during oxidation. In a last step, the Fe-Si clusters get finally totally oxidized (step 6 in fig. 5), leaving a pure $\mathrm{Si}$ pyramid-like defect at the $\mathrm{SiO}_{2} / \mathrm{Si}$ interface, as well as small Fe-rich clusters incorporated in $\mathrm{SiO}_{2}$, surrounding the pyramids, as shown in the STEM-HAADF image 4 in fig. 6.

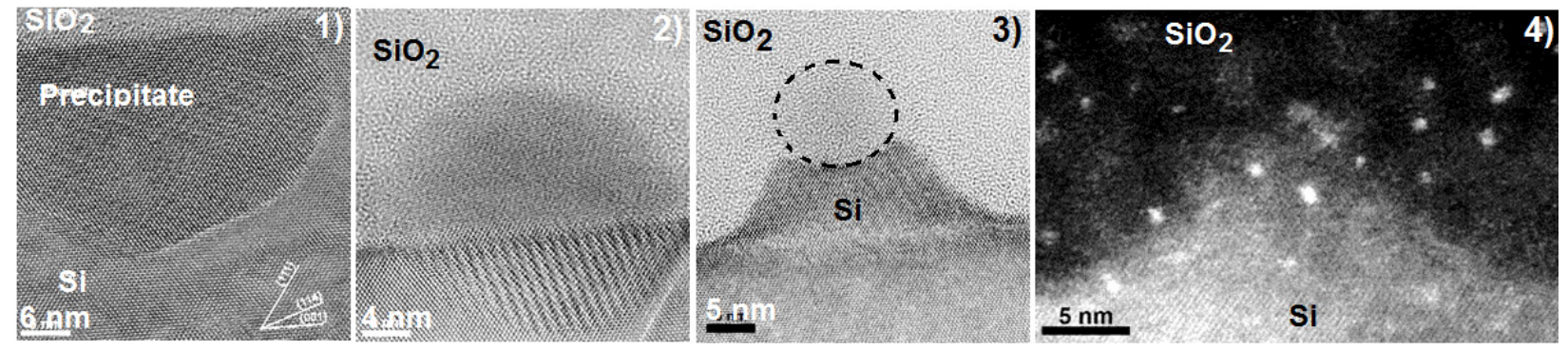

Fig. 6. Cross-sectional HR TEM (1-3) and HR STEM-HAADF (4) obtained on the sample implanted with a dose of $1 \times 10^{15} \mathrm{Fe}$ at $\mathrm{cm}^{-2}$, after annealing (from left to right) 1) at $900{ }^{\circ} \mathrm{C}$ for $5 \mathrm{~min}, 2$ ) and 3) at $900{ }^{\circ} \mathrm{C}$ for $592 \mathrm{~min}$, and 4 ) at $1100{ }^{\circ} \mathrm{C}$ for $12 \mathrm{~min}$. The dash line in image 3 delimitates the interface of a Fe-Si precipitate.

\section{Summary}

W diffusion in Si was studied using SIMS profiles and TEM observations. W diffusion profiles cannot be simulated using standard diffusion mechanisms used for known Si impurities. However, experimental observations could be simulated using a model including two simultaneous diffusion mechanisms, based on three $\mathrm{W}$-point defect reactions: the dissociative and the kick-out reactions, as well as an original reaction leading to the formation of W-Si self-interstitial pair located on the $\mathrm{Si}$ interstitial lattice. Ab initio calculations should be performed in order to confirm the validity of this model. Fe redistribution during the oxidation of Fe-contaminated Si was also studied using SIMS and TEM measurements. Fe atoms are observed to diffuse in $\mathrm{Si}$ for concentrations significantly larger than the Fe solubility limit at the beginning of oxidation. Fe precipitates nucleate and grow at the $\mathrm{SiO}_{2} / \mathrm{Si}$ interface during oxidation, forming $\mathrm{Fe}$ silicides. The silicide precipitates lead to the formation of pyramidal $\mathrm{Si}$ defects at the $\mathrm{SiO}_{2} / \mathrm{Si}$ interface due to a precipitate masking-like effect linked to the oxidation rate difference between silicide clusters and Si.

This work was supported by the French Ministry of Industry in the framework of the project COMET (Grant No. FUI-AAP9-COMET). 


\section{References}

[1] F. Boucard, F. Roger, I. Chakarov, V. Zhuk, M. Temkin, X. Montagner, E. Guichard, D. Mathiot, Mat. Sci. Eng. B 124-125 (2005) 409.

[2] P. Pfäffli, P. Tikhomirov, X. Xu, I. Avci, Y.-S. Oh, P. Balasingam, S. Krishnamoorthy, T. Ma, Microelec. Reliability 52 (2012) 1761.

[3] M. Mekheldi, S. Oussalah, A. Lounis, N. Brihi, Results in Physics 6 (2016) 80.

[4] J.R. Davis, A. Rohatgi, P. Rai-Choudhury, P. Blais, R.H. Hopkins, J.R. Mccormick, Characterization of the effects of metallic impurities on silicon solar cell performance, 13th Photovoltaic Specialists Conference, 1978, pp. 490-495.

[5] D. Gui, Z.X. Xing, Z.Q. Mo, Y. Hua, S. Zhao, IEEE International Conference on Semiconductor Electronics, 2006, pp. 477-480.

[6] Y. Fujisaki, T. Ando, H. Kozuka, Y. Takano, J. Appl. Phys. 63 (1988) 2304.

[7] S. Boughaba and D. Mathiot, J. Appl. Phys. 69 (1991) 278.

[8] K. Graff, Metal impurities in silicon-device fabrication, Springer series in materials science 24, Springer-Verlag, New York, 1995.

[9] H. Lemeke, Proceeding of the Electrochemical Society 94-10 (1994) 695.

[10] A.A. Istratov, H. Hieslmair, E.R. Weber, Appl. Phys. A: Mat. Sci. Process. 69 (1999) 13.

[11] F.A. Trumbore, Bell System Technical Journal 39 (1960) 205.

[12] A. De Luca, A. Portavoce, M. Texier, C. Grosjean, N. Burle, V. Oison, B. Pichaud, J. Appl. Phys. 115 (2014) 013501.

[13] D.J Wong-Leung, J. Eaglesham, J. Sapjeta, D.C. Jacobson, J.M. Poate, J.S. Williams, J. Appl. Phys. 83 (1998) 580.

[14] A. De Luca, M. Texier, A. Portavoce, N. Burle, C. Grosjean, S. Morata, F. Michel, J. Appl. Phys. 117 (2015) 115302.

[15] M. Jacob, P. Pichler, H. Ryssel, J. Appl. Phys. 82 (1997) 182.

[16] G. Mannino, S. Whelan, E. Schroer, V. Privitera, P. Leveque, B. G. Svensson, E. Napolitani, J. Appl. Phys. 89 (2001) 5381.

[17] P.M. Fahey, P.B. Griffin, and J.D. Plummer, "Point defects and dopant diffusion in silicon", in: Reviews of Modern Physics 61 (1989) 289.

[18] P. Pichler, Intrinsic Point Defects, Impurities, and Their Diffusion in Silicon, Springer, Vienna, 2004. 